\title{
Mulheres Enfrentando as Violências: a voz dos operadores sociais
}

\section{Women Facing Violence: the voice of social workers}

Adriana Dewes Presser

Enfermeira Licenciada Mestre em Saúde Coletiva. Professora da Faculdades EST.

Endereço: Rua Guerreiro Lima, n 476, Bairro Santa Catarina, CEP

93214-430, Sapucaia do Sul, RS, Brasil.

E-mail: adewesळpop.com.br

\section{Stela Nazareth Meneghel}

Médica Sanitarista. Pós-doutora em Psicologia Social. Professora do Programa de Pós graduação de Saúde Coletiva da Universidade do Vale do Rio dos Sinos - Unisinos.

Endereço: Rua Santo Antonio, 6II ap. 32, CEP 90220-oII, Porto Alegre, RS, Brasil.

E-mail: meneghelळunisinos.br

\section{Élida Azevedo Hennington}

Médica sanitarista. Doutora em Saúde Pública. Professora do Instituto de Pesquisa Clínica Evandro Chagas/Fiocruz.

Endereço: Av. Brasil, 4365, Manguinhos, CEP 21045-900, Rio de Janeiro, RJ, Brasil.

E-mail: elidahenningtonळipec.fiocruz.br

Financiamento: Conselho Nacional de Desenvolvimento Científico

e Tecnológico. Projeto comtemplado pelo Edital 045-CNPq. Pro-

cesso: $401764 / 2005^{-2}$.

\section{Resumo}

Este artigo tem o objetivo de esclarecer a rota crítica de mulheres do município de São Leopoldo no enfrentamento da violência, por meio da análise das práticas discursivas de um grupo de trabalhadores de instituições sociais. Realizou-se uma seleção intencional de instituições dos setores saúde, educação, policial, jurídico-legal e comunitário e foram entrevistados dois representantes de cada setor. A partir das práticas discursivas dos operadores, percebemos que a violência praticada contra as mulheres é um problema de elevada frequência e baixa resolubilidade institucional. No processo da rota crítica - o caminho percorrido pelas mulheres para romper com a violência - muitas não recebem o acolhimento nos serviços. Apesar da criação do Centro de Referência para Mulheres, ainda há muito a ser feito para efetivar as políticas públicas. Os depoimentos dos trabalhadores sociais foram enunciados a partir da posição institucional que ocupam, e, nesses discursos, eles minimizaram os pedidos de ajuda das mulheres, culpabilizando-as. Os operadores ligados às organizações comunitárias foram os mais solidários e compreensivos. Os resultados da pesquisa mostram que não há uma única rota ou itinerário ideal; pelo contrário, a rota percorrida pelas mulheres é longa, dolorosa e nem sempre eficiente. Nem todas as rotas empreendidas pelas mulheres em São Leopoldo puderam ser conhecidas, porém o fato de outros serviços estarem sendo disponibilizados na cidade, certamente possibilitará o traçado de outros caminhos.

Palavras-chave: Violência intrafamiliar; Violência de gênero; Práticas discursivas; Rota Crítica. 


\section{Abstract}

This article investigates the critical path followed by women facing violence in the city of São Leopoldo through the analysis of discursive practices of a group of workers from social institutions. An intentional selection of institutions was carried out, including the following areas: health, education, police force, law and community. Two representatives of each sector were interviewed. Based on the workers' discursive practices, we noticed that the violence that is perpetrated against women is a problem of high frequency and low institutional resolution. Throughout the Critical Path process - the way followed by women in order to break with violence - many users are not sheltered by the services and, despite the creation of a Reference Center for Women, there is still a lot to be done to enforce the public policies. The social workers' discourses were enunciated from the institutional position they occupy, and in these discourses they minimized the women's request for help, saying that they were guilty. Workers from community organizations were the most sympathetic ones. The results show that there is not a single path or an ideal itinerary; rather, the path followed by many women is long, painful and, sometimes, inefficient. Not all the paths followed by the women in São Leopoldo could be investigated; however, the fact that other services are becoming available in the city will certainly enable the design of other ways.

Keywords: Intrafamily Violence; Violence Against Women; Discursive Practices; Critical Path.

\section{Introdução}

A violência contra a mulher é um grave problema social que afeta grandes contingentes populacionais. Várias designações têm sido usadas para se referir a esse tipo de violência, podendo-se considerar violência de gênero a categoria mais abrangente e utilizada (Saffiotti, 2004). No início dos anos 1990, a violência de gênero foi reconhecida como um problema de saúde pública pela Organização Mundial de Saúde, que a considera um dos tipos mais generalizados de abuso de direitos humanos e o menos reconhecido (Krug e col., 2003; Gamel, 1997; Paltiel, 1993).

A designação violência de gênero implica a desnaturalização da violência e a compreensão de que ela é produto da organização social e está fundamentada nas desigualdades entre os sexos, constituindo-se um campo de luta estruturada pelas diferenças de poder entre homens e mulheres (Heise, 1994). Segundo Joan Scott (1990), as feministas começaram a usar a palavra gênero como maneira de se referir à organização social da relação entre os sexos. Além disso, a palavra indica uma rejeição ao determinismo biológico e aos essencialismos, enfatiza o aspecto relacional das definições normativas de feminilidade e masculinidade e é um modo primordial de significar relações de poder.

Dentro das várias correntes do pensamento feminista, podemos citar como fundamental, em primeiro lugar, a que entende a desigualdade pautada em gênero como decorrente do patriarcado, entendido como sistema de poder ainda vigente na sociedade atual, que perpetua a dominação/exploração de mulheres (Saffiotti, 2004); um segundo grupo é o do feminismo marxista; e o terceiro inspira-se na psicanálise para explicar a produção e a reprodução de identidades de gênero.

Gênero é uma categoria histórica que pode ser concebida em várias instâncias: como aparelho semiótico, como símbolos culturais carregados de significados, como hierarquias de poder, como uma gramática sexual regulando tanto relações heterossexuais quanto homossexuais. Em síntese, gênero é a construção social do masculino e do feminino (Scott, 1990; Saffiotti, 2004, 2005). Dentro da família, as desigualdades produzidas por gênero e idade são as principais determinantes das relações violentas que nela se constituem, enquanto na sociedade, além de gênero, a violência é exacerbada pelas condições de classe e raça e 
diferenciada de acordo com o espaço público/privado (Brasil, 2003; Giffin, 2002; Saffiotti, 2005).

Estudos apontam para o uso mais intenso dos serviços de saúde, ambulatoriais e hospitalares, por mulheres em situação de violência (Ângulo-Tuesta, 1997; Deslandes e col., 2000; Hyman e col., 2000; Kronbauer e Meneghel, 2005; Schraiber e D'Oliveira, 2002). Apesar disso, a violência de gênero ainda é pouco reconhecida nos serviços de saúde, e muitos trabalhadores dessa área realizam o atendimento das agressões físicas deixando de atender as manifestações emocionais da violência, de orientar e de dar o devido encaminhamento aos casos. Muitas mulheres em situação de violência procuram os serviços de saúde apresentando queixas variadas, e muitas delas são diagnosticadas como polissintomáticas e hipocondríacas, entre outras denominações pejorativas (Flitcraft e col., 1992; Gamel, 1997; Stark e Flitcraft, 1996; Tilden e col., 1994).

Dentre as iniciativas realizadas para compreender a violência contra a mulher e os mecanismos que as levam a romper com a situação de violência destaca-se a proposta desenvolvida pela OPAS e denominada Rota Crítica (Sagot, 20oo). A Rota Crítica foi realizada em dez países da América Central e do Sul e em três países andinos, entre 1996 e 1998, a partir de um protocolo elaborado em conjunto por pesquisadores, ativistas e funcionários de instituições dos países participantes, visando contribuir com a prevenção, o combate e a erradicação da violência contra as mulheres (Sagot e Shrader, 1998). Essa investigação permitiu conhecer os fatores que impulsionaram as mulheres a buscar ajuda, as dificuldades encontradas para levar adiante essa decisão, as percepções sobre as respostas institucionais e os significados da violência.

Apesar da existência de serviços públicos e comunitários voltados para a atenção às mulheres em situação de violência em muitos países latino-americanos, observa-se que muitas das que decidiram ou buscaram efetivamente romper com situações de violência, não encontraram amparo, enfrentando uma trajetória marcada por dificuldades, desestímulo, inexistência ou falta de acesso às instituições e serviços (Sagot, 200o). O Brasil não foi contemplado na investigação da Rota Crítica, fato que estimulou a realização de estudo semelhante à proposta da OPAS em São Leopoldo, município da região metropolitana de Porto Alegre (RMPA), estado do Rio Grande do Sul, que apresenta elevados índices de violência (Hennington e col., 2008; Soethe e col., 2001). Este artigo faz parte de um projeto maior denominado "Violência intrafamiliar e de gênero: o caminho das mulheres no enfrentamento ao sofrimento"'.

A pesquisa teve como objetivo conhecer as ações e as trajetórias de mulheres na busca de alternativas para a superação da situação de violência no município de São Leopoldo, por meio da análise das práticas discursivas dos operadores de Instituições que trabalham com violência de gênero no município.

\section{Percurso Metodológico}

Foram analisadas as práticas discursivas sobre a violência de gênero a partir da perspectiva de um grupo de trabalhadores de instituições sociais que atuam com violência em São Leopoldo.

Os discursos são práticas sociais, porém, a partir de Foucault (1997), não se falaria mais tanto de discursos, mas de práticas discursivas que, para ele, compreendem regras anônimas, constituídas no processo histórico, que em uma época concreta e em grupos ou comunidades específicas, definem as condições que possibilitam qualquer enunciação. As práticas discursivas implicam o fato de que falar é fazer algo, é criar aquilo de que se fala, quando se fala (Iñiguez, 2005).

A ordem discursiva nomeia interesses e estratégias em luta e, ao mesmo tempo contrapõe-se a outros discursos, interesses e projetos, constituindo teias discursivas e demonstrando a pluralidade do real, a heterogeneidade e a possibilidade de transformações ao longo do tempo. O discurso enquanto objeto linguístico e sócio-histórico, constitui um referencial e, enquanto modo de construção discursiva, permite diferentes formas de apreensão de efeitos sociais (Moraes, s.d.).

As práticas discursivas constituem um instrumental teórico e metodológico interdisciplinar, capaz de permitir a compreensão dos projetos de diferentes atores sociais. Buscam o sentido ou os sentidos pro-

1 MENEGHEL, S. N.; HENNINGTON, E. A. Violência intrafamiliar e de gênero: o caminho das mulheres no enfrentamento ao sofrimento. 2005 . 
duzidos pelo sujeito ao elaborar um discurso, as suas intenções e a forma como é recebido por quem ouve ou lê suas palavras. $\mathrm{O}$ conceito de prácticas discursivas remete aos momentos de ressignificações, de rupturas, de produção de sentido e corresponde aos momentos ativos do uso da linguagem, nos quais coexistem a ordem e a diversidade. Podemos definir práticas discursivas como linguagem em ação, ou seja, as maneiras a partir das quais as pessoas produzem sentidos. As práticas discursivas têm como elementos constitutivos: a dinâmica - os enunciados orientados por vozes -; as formas, que são os gêneros de fala e os conteúdos, que são os repertórios interpretativos (Spink, 2000, 2004).

Spink (2004) afirma que o discurso produz um defrontamento entre os diferentes atores sociais e as vozes. É a um só tempo o reconhecimento de outras vozes e de outros sujeitos discursivos, construindo tensões e podendo provocar mudanças.

Na cidade de São Leopoldo, foram identificados serviços do setor público e não-governamental (ONG) que atuam com a temática da violência. A seleção das instituições foi intencional, considerando o histórico de atendimento a pessoas em situação de violência e a representatividade no município, prevendo a participação de um ou dois representantes de cada instituição, os mesmos critérios utilizados no estudo original da Rota Crítica (1998). O protocolo de investigação usado foi o proposto no trabalho da Rota Crítica (Sagot e Shrader, 1998), traduzido e adaptado à realidade local. Compreende um guia de entrevistas semiestruturadas, específico para cada tipo de prestador. A pesquisa foi aprovada pelo CEP/Unisinos.

Fizeram parte da amostra: o Centro Ecumênico de Evangelização, Capacitação e Assessoria (CECA) e Promotoras Legais Populares (PLP), representando o setor não-governamental; o Hospital Municipal (Projeto Sentinela e Serviço de Emergência), representando o setor Saúde; o Posto da Mulher da Primeira Delegacia de Polícia Civil e o Serviço de Psicologia da $1^{\text {a }}$ Delegacia de Polícia Civil, representando o Setor Policial; o Ministério Público e o Poder Judiciário, representando o setor Jurídico-Legal; e a Secretaria Municipal da Educação representando o Setor Educativo.

Os operadores sociais vinculados às instituições citadas e participantes da pesquisa foram: uma advogada, duas promotoras legais populares (PLP), uma médica, uma enfermeira, uma escrivã de polícia, duas estagiárias de psicologia, uma promotora, um juiz de direito, uma pedagoga e uma teóloga. Cada um desses operadores será mencionado no texto de acordo com a função social que desempenha, incluindo numeração sequencial quando houver mais de um sujeito.

As instituições foram contatadas por telefone, quando eram esclarecidos os objetivos da pesquisa e se agendava a entrevista. A entrevista compreendeu perguntas relacionadas ao trabalho, à experiência com mulheres afetadas pela violência e às concepções sobre a violência de gênero. Foram transcritas e organizadas num corpus, do qual constam os textos transcritos e documentos institucionais. Após a organização do corpus, o material foi submetido a inúmeras leituras em busca dos temas principais para compor os repertórios interpretativos, averiguar as posições dos falantes e analisar as contradições e incoerências nos enunciados.

Os repertórios interpretativos compreendem as unidades analíticas básicas das práticas discursivas: vocábulos, termos, expressões, metáforas e figuras de linguagem, que demarcam o rol de possibilidades das construções discursivas, tendo por parâmetros o contexto em que essas práticas são produzidas e os estilos gramaticais específicos. Repertórios são uma ferramenta analítica que permite identificar as inconsistências e as diferenças nos discursos de um ou vários falantes. São usados quando se quer mostrar a importância do agenciamento humano na linguagem, que não pode ser entendido se for feita a análise apenas dos conteúdos enunciados. Embora mais fragmentados que os discursos, os repertórios oferecem aos falantes uma ampla gama de oportunidades retóricas e permitem localizar as posições de onde os falantes se reportam (Edley, 2001; Iñiguez, 2005; Meneghel e Iñiguez, 2007; Wetherell e Potter, 1996).

A posição do sujeito é o que conecta os repertórios ou discursos às identidades e às subjetividades. Posições de sujeito podem ser definidas como localizações dentro da conversação, que de certa forma podem mudar dentro ou entre os discursos, o que não quer dizer que as posições simplesmente sigam o discurso, mas que podemos nos subjetivar na medida em que falamos. Entender a posição do sujeito no discurso significa perguntar "quem está implicado em um determinado discurso ou repertório”. Refere-se aos 
diversos status, lugares, posições que são ocupadas em regimes particulares para que algo se torne dizível, audível e operável (Edley, 2001).

Outra ferramenta usada na análise foram os dilemas ideológicos que sinalizam a natureza dilemática da linguagem, usada em ampla variedade de propósitos retóricos. Segundo Billig (1988), uma das características da linguagem comum é que ela não é totalmente coerente ou integrada, mas inconsistente, contraditória e fragmentada. Essas contradições ajudam a resolver impasses presentes nos diálogos, mas também podem evidenciar posições "politicamente incorretas" disfarçadas como nos estudos de Wheterell e Potter (1992) sobre racismo, em que os falantes em alguns turnos de conversação negavam as atitudes racistas e, em outros, evidenciavam-nas.

\section{A Violência Contra a Mulher em São Leopoldo}

O município de São Leopoldo enfrenta uma situação de elevados índices de violência, agudizada pela degradação das condições gerais de vida, emprego, educação, saúde, habitação e infraestrutura urbana (Hennington e col., 2008; Soethe e col., 2001).

A violência de gênero tem sido considerada um fenômeno amplamente disseminado, que não respeita fronteira de classe social, etnia, religião, idade e escolaridade. Estima-se que pelo menos um quinto da população feminina mundial já tenha sofrido violência física ou sexual em algum período da vida (Krug e col., 2003). Em São Leopoldo, todos os operadores entrevistados concordam que a violência contra a mulher é uma situação de elevada magnitude na região, adquirindo um caráter endêmico e podendo ser considerada um problema de saúde pública: "[...] acho que a violência é comum não só em São Leopoldo como em todo lugar, é um problema social e eu acho que éum problema de saúde pública” (Jurídico-legal 2). "Eu acho que São Leopoldo é uma cidade violenta em todos os sentidos. É uma cidade de origem alemã, com uma cabeça muito conservadora e puritana" (ONG 1). Nessa afirmação, a depoente, possivelmente se referia às origens históricas da colonização da cidade, que foi predominantemente alemã, embora não se mantenha atualmente. O conservadorismo está associado a um tipo de organização social com sólida referência aos valores ético-cristãos, na solidariedade étnica e nos princípios da ordem e da operosidade (Shallenberger, 2007).

Os operadores sociais mencionaram enfaticamente a violência psicológica, geralmente associada a outros tipos de violência (Kronbauer e Meneghel, 2005; Strey, 2001). No repertório utilizado pelos trabalhadores sociais, apareceram palavras de uso cotidiano e coloquial como no relato de uma Promotora Legal Popular: "violência psicológica é aquela coisa de chamar de vaca, né?” (ONG 2). A violência psicológica é a menos notificada e reconhecida, embora de alta frequência. "a violência psicológica é direto. Muitas vezes nem chega até aqui"; "É mais ou menos parelho, só que a violência psicológica não chega a juízo. [...] a gente fica sabendo da ocorrência de violência psicológica lá na vara de família” (Jurídico-legal 1); “Tem muita violência sigilosa, que não deixa marcas, a violência psicológica" (ONG 2).

Houve unanimidade ao afirmar a inexistência de dados estatísticos confiáveis a respeito da violência contra a mulher no Município: "Não há estatística de quantos processos passam por aqui, pois eles entram na carga junto com outros processos. Eu não tenho estatística, mas o volume é muito grande" (Jurídicolegal 2). 0 Posto da Mulher, que funciona junto à Delegacia de Polícia, não registra as ocorrências dos atendimentos, fato apontado há anos pelo movimento de mulheres da região.

Pesquisadora: Quantas pessoas com este tipo de problema são atendidas neste serviço mensalmente? Essa estatística eu não tenho. [...] O meu cartório é dentro da $1^{a}$ Delegacia, não é um órgão separado. Então eu não tenho a minha estatística. Eu tenho as ocorrências que eu recebo do chefe do cartório da $1^{a}$. Então assim, pra eu ter estatística eu teria que ir lá ver quais são as vítimas mulheres, entendeu? (Policial 1).

Os trabalhadores de saúde entrevistados referiram que notificam as situações de violência sexual, porém não registram e não atendem quaisquer outros tipos de violência. Em relação ao uso de formulários específicos para o registro dos atendimentos, verificamos que apenas dois setores amostrados utilizam: a ONG e o serviço de psicologia ligado à Delegacia de Polícia.

Ao tentar entender a violência praticada contras as mulheres em São Leopoldo, percebemos, como outros autores (Chesnais, 1999; Minayo e Souza, 1999), que ela 
não é somente um problema de justiça, de educação ou de saúde, mas representa um verdadeiro mosaico formado por diferentes componentes e determinantes.

\section{A Rota Crítica das Mulheres no Enfrentamento à Violência}

Entender a Rota Crítica nas suas peculiaridades locais implica conhecer os fatores que impulsionam as mulheres a buscar ajuda, bem como as dificuldades para levar adiante tal decisão. O enfrentamento da violência intrafamiliar e de gênero começa com a decisão e a determinação das mulheres de se reapropriar de suas vidas e a de seus filhos 0 primeiro passo para sair da situação de violência pode ser considerado o romper do silêncio e ocorre quando as mulheres decidem revelar essa situação a uma pessoa fora do âmbito doméstico (Sagot, 200o). Segundo Fagute e Landis (2005), 71\% das mulheres narram a situação de violência a alguma pessoa próxima, familiar, amigo ou vizinho, enquanto apenas $38 \%$ procuram os órgãos policiais e $24 \%$, os serviços de saúde.

No estudo da Rota Crítica realizado nos países americanos observou-se que muitas mulheres iniciaram a rota quando os filhos sofreram maus-tratos, situação semelhante à que foi relatada em São Leopoldo: "Têm mulheres também que agüentaram violência a vida inteira e que o homem mexe com o filho ela reage" (ONG 1); "Teve um caso de uma mulher que apanhou direto, durante 23 anos, de tudo que é maneira imaginável, mas quando a filha foi abusada sexualmente, ela disse basta. Ela só conseguiu reagir quando a filha foi vítima" (ONG 2).

As mulheres não iniciam a rota por inúmeros motivos: medo das ameaças e agressões, dependência econômica, crença que continuar com o companheiro é melhor para os filhos, preconceitos e estereótipos de gênero, familiares ou culturais. Ouçamos o entendimento dos operadores acerca dessas dificuldades: " $\varepsilon u$ acho que por medo, ameaças de morte, para preservaro núcleo familiar: pai, mãe e filhos juntos; a questão financeira conta muito: porque é um barraco, mas tem que dividir; medo de ficar sozinha, sem um companheiro" (ONG 1). "Quando a mãe relata a situação de violência ela pede que não seja colocada em nenhuma ata, que nenhum registro seja feito, por medo"(Educação 1).
Tradicionalmente, tem se considerado que a denúncia em Delegacia de Polícia é um procedimento que a mulher em situação de violência precisa realizar, porém essa atitude nem sempre é eficaz, como já pontuado em outros trabalhos (Meneghel e col., 2005). Em São Leopoldo, os operadores disseram que uma das primeiras ações das mulheres é a denúncia nas Delegacias de Polícia, onde é redigido um Boletim de Ocorrência (BO) para iniciar o inquérito policial. Esse procedimento pode ser desdobrado em duas ou mais idas à delegacia ou a outros locais para a realização de exames complementares e do laudo pericial. 0 município não realiza o laudo e as mulheres são encaminhadas para a cidade vizinha. Isso significa, além do sofrimento emocional, despesa com locomoção, recursos de que nem sempre elas dispõem e absenteísmo no trabalho.

Pesquisadora: Podes contar como foi alguma dessas experiências vivida com uma dessas mulheres e o encaminhamento que foi dado?

Uma coisa com a qual a gente sempre se deparou muito foi a questão do encaminhamento, né? As mulheres vinham vitimadas pela violência, aí tu encaminha elas, que é mais uma violência: um manda p'rum lado, outro manda pra outro ... então é uma via sacra muito grande dessas mulheres (ONG 2).

Nas múltiplas idas e vindas aos serviços, muitas usuárias não recebem necessariamente o acolhimento de que precisam, mesmo observando-se que, em geral, os trabalhadores desses serviços são mulheres. Segundo Ostermann (2006), as policiais têm uma probabilidade maior de serem alocadas em uma Delegacia da Mulher, embora muitas delas não desejem isso.

Pesquisadora: Qual é o seu trabalho?

Desde que eu fui designada para cá, o meu chefe, não sei por que, chegou e me escolheu e disse que eu trabalharia no posto da mulher. Teve épocas em que pedi pra sair, porque estava cansada, chateada, estressada, mas os delegados nunca me tiraram, sempre me seguraram, só me prometiam [...] Atévou te dizer, há um preconceito na Polícia Civil, dos próprios policiais não quererem trabalhar no Posto da Mulher. Então eu sempre fui ficando ... não é que eu não goste [...] (Policial 1). 
Denunciar e relatar a pessoas estranhas a violência sofrida no âmbito domiciliar constitui, para muitas mulheres, uma ameaça em potencial à sua imagem pública, mesmo quando o ouvinte é um profissional capacitado. Ao implantar as delegacias da mulher, havia uma expectativa de que as profissionais nas delegacias fossem mais sensíveis ao pedido de ajuda, fato que nem sempre acontece (Ângulo-Tuesta, 1997; Ostermann, 2006). "Teve um tempo que a mulher era 'estuprada duas vezes', como a gente dizia. Primeiro pelo estuprador e depois pelas palavras de quem atendia ela" (ONG 2). A violência institucional não acontece apenas em países de Terceiro Mundo. Em uma análise de usuários de serviços de proteção às mulheres no Reino Unido, a maioria das entrevistadas declarou que não foi suficientemente ouvida, compreendida ou acreditada pelos prestadores de serviços, e metade delas continuou desprotegida e em situação de perigo por longos períodos (Hague e Mullender, 2006).

Em relação ao fluxo e aos trâmites legais, os operadores afirmaram que em situações limite as mulheres pressionam os órgãos públicos, buscando, por exemplo, o Ministério Público, antes da audiência de conciliação, como forma de proteção diante das ameaças de morte e de violência extrema, quando elas se sentem em perigo iminente: "Elas não têm paciência [grifo nosso] para esperar a audiência”. Esse operador alertou para a possibilidade de intervenção direta do delegado: "Se é um caso grave o próprio delegado pode pedir a prisão do cara porque o tipo, sei lá, quebrou a mulher inteira ou quebrou a casa inteira e os filhos, enfim..." (Jurídico-legal 2). Na voz do operador, pode haver intervenção rápida com pedido de prisão para o agressor. Essa afirmação contrasta com a parte inicial do depoimento em que ele dizia que os processos "morrem" na Instituição, referindo-se à morosidade dos trâmites legais.

\section{A Construção da Rede de Atendimento às Mulheres}

No ano de 2005, o município de São Leopoldo passou a discutir a criação de uma Rede de Atendimento e Apoio a Mulheres em Situação de Violência, incluindo um Centro de Referência que resultou na criação do Centro Jacobina para prestar atendimento às mulheres em situação de violência.
A proposta da rede de atendimento à mulher em situação de violência no município ainda se encontra em construção. Os discursos dos operadores destacam a desestruturação da rede e manifestam conhecimento apenas do "pedaço da rede" que compete ao seu setor de atuação; eles desconhecem o percurso que a mulher percorre em busca de ajuda, quais os recursos mais eficientes que ela poderia utilizar ou as maneiras mais ágeis e menos dolorosas.

Pesquisadora: Nesse processo de denúncia tu tens idéia de a quantas pessoas diferentes a vítima precisa se dirigir?

A princípio, ah... eu só sei que ela vai pra delegacia, vai registrar ocorrência e aí ela vai ser ouvida, eu não sei se no mesmo dia ou às vezes vão marcar uma data pra ela ser ouvida. Se ela tiver que fazer algum exame daí ela vai ser encaminhada pra exame. E aí, posteriormente, ah... ela é comunicada da audiência de conciliação e ela vai encontrar comigo e com o juiz... (Jurídico-legal 2).

Muitos operadores admitiram que não conseguem participar da rede de atendimento às mulheres em situação de violência, eles justificaram este fato, enunciando longos arrazoados, tentando expor as limitações acarretadas pela sobrecarga de trabalho: "você acaba atropelado pelos processos" (Jurídico-legal 2) e atribuem as dificuldades na resolução da violência de gênero a questões conjunturais, como o excesso de trabalho, o estresse, a burocracia, a falta de envolvimento das outras instituições integrantes da rede, fazendo com que cada um aja isoladamente, restrito à sua área de atuação.

Pesquisadora: Na tua opinião o que poderia ser feito para melhorar a resposta desse setor [jurídico] em casos de mulheres que têm sido maltratadas? Enfim ...,eu acho que talvez nós poderíamos, ah, tipo se engajar mais na rede, talvez eu teria que fazer isso, talvez eu esteja falhando, mas é uma cois a que a gente acaba tipo sendo atropelado pelos processos, pela demanda e tu até gostaria de fazer muita coisa, fazer muito mais, né... claro que a rede também não tem buscado o nosso serviço... então cada um tenta fazer uma coisa, a sua parte, sozinho e tenta fazer um pouquinho (Jurídico-legal 2).

A rede municipal de atendimento às mulheres em situação de violência só irá funcionar efetivamente 
se houver articulação entre os atores/instituições. Muitos operadores consideram as parcerias imprescindíveis para compor o trabalho, mas desconhecem os possíveis parceiros "têm outros órgãos, mas eu não tenho completamente de memória” (Jurídico-legal 1) e não mostram disponibilidade para se inserir no trabalho interdisciplinar e interinstitucional: " $E u$ recebi outro dia um convite duma ONG ou associação. Eu tava pensando até em entrar em contato pra ver que tipo de atendimento é" (Jurídico-legal 2). Algumas instituições são vistas como concorrentes: "A gente conheceu um outro local que trabalha com mulher vítima de violência aqui em São Leopoldo que disse que a gente tava roubando a clientela deles" (Policial 2).

Apesar das dificuldades, pode-se afirmar que ocorreram avanços nos últimos tempos no município. Após a mudança na administração local, foram criados a Coordenadoria Municipal da Mulher, o Centro de Referência e o Centro Jacobina, cujas equipes têm procurado construir parcerias entre as diferentes instituições que operam com a violência, embora haja muito a ser feito para efetivar as políticas de enfrentamento da violência.

\section{O Que Dizem os Discursos: dilemas e contradições}

O discurso ou repertório técnico - quer seja o jurídico, policial ou médico - reproduz a desigualdade social no âmbito dos serviços ou instituições específicos e o processo de efetivação desses discursos passa pelo uso de artifícios retóricos como a exterioridade, na qual ocorre a descrição de uma situação como se ela fosse um fato independente do agente que a produz; além disso, os fatos são usados como se fossem dados primários (Izumino, 1998).

O discurso jurídico e a moralidade que ele produz estão expressos nas falas e, especialmente, nos laudos periciais. Esses laudos e relatórios estão repletos de termos específicos e linguagem técnica especializada, que os psicólogos sociais têm chamado de repertório técnico ou repertório empirista (Gilbert e Mulkay, 1985; Wheterell e Potter, 1996). O discurso técnico constitui a prática jurídico-policial tida como objetiva, descrevendo um ritual que se caracteriza por ações rotineiras e normas. A argumentação técnica conduz a uma idéia de que a intervenção dos agentes se reduz à aplicação da lei com base em fatos. Os membros da comunidade são meros agentes, obrigados a realizar certas ações em cumprimento à lei e à maquinaria institucional:

Pesquisadora: No processo de denúncia, a quantas pessoas a mulher precisa se dirigir?

Se ela chegou num horário que dá pra fazer o registro, então tu faz. Se não, o colega vai dizer: olha, agora não posso, vem amanhã e procura a funcionária do cartório... assim, ocorrência e encaminhamento pra os exames eles dão na hora, agora, aquela parte de ouvir em termo de depoimento e pedido de medida protetiva, se a coisa for muito tumultuada eles vão orientar: não, tu vem amanhã, no horário tal [...] (Policial 1).

Outras estratégias que fazem parte do repertório da comunidade jurídica são a retórica ética, a justificativa e a construção de consenso. A retórica utiliza como princípios básicos para a aplicação da lei a ética e a justiça, que é considerada igualitária nos seus procedimentos. A construção do consenso apoia-se na premissa de que os fatos "científicos", jurídicos e policiais, entre outros, são construídos pela superposição de argumentos entre vários atores (Serra, 2005).

Nesta pesquisa, os depoimentos foram enunciados a partir da posição que os operadores ocupam nos sistemas jurídico-policial, de saúde, educação e comunitário. Nas conversas que ouvimos, eles não esclareceram suas posições na condição de juízes, promotores, policiais ou médicos. Embora haja atualmente um discurso social de gênero, graças às reivindicações do movimento de mulheres, agregada no último ano com o debate em torno da Lei Maria da Penha, as falas estão eivadas de dilemas ideológicos e/ou contradições. Um deles é o da culpabilização da mulher, ou seja, depois de mobilizar pessoas, abrir processos, exigir proteção, a mulher desiste de seguir a demanda, onerando os serviços e obstaculizando o funcionamento adequado do sistema.

Pesquisadora: Como é o atendimento à mulher vítima de violência?

Há um índice muito elevado de desistência. É muito maior e já beira os 9o\%, porque elas chegame dizem: não, eu só queria dar um susto e quero terminar o processo. Ou já se separaram e voltaram a viver juntos. A maior parte vai para extinção, pou- 
cos processos é que terminam com aplicação de pena (Jurídico-legal 1).

Pesquisadora: Alguma vez já atendeu alguma mulher vítima de violência?

[...] Aí elas tiram o processo por causa dos filhos, porque têm que alimentar os filhos, então é uma coisa assim, é, na verdade, é um problema social, né?, de base (Jurídico-legal 2).

O fato de que apenas um pequeno percentual de processos termina com aplicação da pena é atribuído à conduta das mulheres que desistem de representar judicialmente contra o agressor. 0 operador, no entanto, não faz qualquer menção à violência institucional, que inclui a morosidade do sistema, a incapacidade de proteger a vítima, a necessidade de repetir a história incontáveis vezes, de percorrer inúmeros locais, o desrespeito e a minimização da gravidade dos fatos.

Outra maneira de desprezar o pedido de ajuda da mulher, utilizado pelos sujeitos que fazem coro à ideologia patriarcal (Saffiotti, 2005; Scott, 1990), que ainda se faz presente nas declarações de alguns operadores pauta-se nos estereótipos de gênero: "Por incrível que pareça, algumas mulheres, se o homem não usa de um pouco de violência, elas acham que ele está deixando de gostar [dela]"(Jurídico-legal 1).

Muitos operadores possuem a convicção de que as mulheres denunciam os maridos agressores de modo leviano, como se quisessem apenas assustá-los e depois encerrar o processo, de certa forma usando a instituição de modo pouco conseqüente. Eles se queixam de serem usados por essas pessoas, expressando o desagrado que esses fatos produzem.

Pesquisadora: Que modificações na legislação ou nas políticas facilitariam seu trabalho?

A gente às vezes fica fazendo papel de bobo, perdendo tempo, porque daí tu dá todo um, hã, tipo... dispensa toda uma pauta de audiências, uma tarde inteira pra ouvir essas pessoas como se aquilo fosse uma coisa grave pra chegar lá e ela dizer: não doutora, eu não... a gente vai tentar de novo, ou vou dar uma chance (Jurídico-legal 2).

Na sociedade atual, as práticas jurídicas classificam os comportamentos sociais de modo a categorizar as pessoas e, assim, organizar de forma racional e po- sitiva a produção da verdade jurídica. Os comportamentos sociais são organizados em estereótipos, do mesmo modo que em outras esferas sociais - a escola, a família, o trabalho. Segundo Couloris (2004), o sistema jurídico age de acordo com o que a sociedade espera dele, observando as pessoas que lhe cabe ouvir, examinar e julgar. Não se atém só aos fatos jurídicos, mas constrói um saber sobre os indivíduos, classificando-os em normais, perigosos ou honestos. 0 conceito de credibilidade ou idoneidade moral é composto de significados de gênero, raça e classe. Dessa maneira, ainda hoje, as mulheres são analisadas em relação à sua vida sexual, enquanto os homens são julgados de acordo com sua disposição para o trabalho. Conceitos e estereótipos de gênero impregnam o discurso dos operadores que falam a partir de uma posição de classe e gênero, e mesmo quando são mulheres, falam do ponto de vista do poder adulto, branco, rico e masculino (Saffiotti, 2005).

De acordo como o trabalho de Sagot (200o), os operadores que se mostraram mais solidários e compreensivos foram os militantes de movimentos sociais, organizações comunitárias de base e trabalhadores sociais exercendo funções nas políticas públicas para a mulher. Eles descreveram o trabalho que realizam nos seguintes termos:

Pesquisadora: Tem alguma forma de registrar os casos detectados de violência intrafamiliar?

Uma equipe multidisciplinar estudava o caso e orientava, encaminhava. Porque, por exemplo, há casos que são tão delicados que fazer uma ocorrência policial pode estragar tudo. Então, antes de orientar a vítima a registrar uma ocorrência policial a gente fazia outras coisas: a questão do fortalecimento, da autoestima, o encaminhamento para uma independência econômica. Porque a gente via mulheres que faziam a ocorrência policial e desistiam dela depois. Ou que o agressor vai ficar sabendo e pode matar a mulher por isso. Então a gente ajuda ela a planejar a vida dela. "Como nós vamos planejar a tua vida a partir do momento em que tu decidir te separar dele?" [...] Aí, quando a gente estava segura do que fazer, dava o encaminhamento de registrar ocorrência, procurar assistência jurídica, ajuizar um processo (ONG 1). 


\section{Considerações Finais}

Nesta pesquisa, ao ouvir os operadores sociais, constatamos que a rota percorrida pelas mulheres para enfrentar a violência é longa, pontilhada de avanços e recuos e nem sempre efetiva. Não há uma única rota e nem todas as rotas empreendidas pelas mulheres em São Leopoldo puderam ser conhecidas, porém o fato de outros serviços estarem sendo disponibilizados na cidade possibilitará o traçado de outros e novos caminhos. Além disso, a mudança na legislação, com a introdução da Lei Maria da Penha, certamente produzirá efeitos ainda não avaliados.

A criação da Rede de Atendimento e Apoio a Mulheres em Situação de Violência ainda se encontra em construção, porém certamente qualificará os serviços de atenção às mulheres no município e poderá trazer novas perspectivas às políticas públicas.

Nesta pesquisa, ouvimos os operadores a partir da posição que ocupam nos sistemas jurídico-policial, saúde, educação e comunitário. Embora circule atualmente um discurso social de gênero, um discurso "politicamente correto", as falas estão eivadas de dilemas ideológicos e contradições. Uma delas é a culpabilização da mulher; outra é manter os estereótipos de gênero. Esses dilemas impregnam o discurso dos homens e mulheres que entrevistamos e mantém o ponto de vista do poder adulto, branco, rico e masculino.

Os operadores desconhecem a totalidade do percurso que a mulher vítima de violência percorre para conseguir proteção para si e para os seus filhos. Além disso, muitos desses operadores não participam da rede de atendimento às mulheres em situação de violência atuando de maneira isolada.

Os militantes de movimentos sociais, organizações comunitárias de base e trabalhadores sociais exercendo funções nas políticas públicas para a mulher foram os atores mais solidários e compreensivos.

Conceber o poder formado por práticas discursivas, estratégicas, descontínuas e heterogêneas nos permite captar as alterações, os embates e a historicidade de conceitos como os de violência de gênero (Couloris, 2004). Os discursos institucionais são perpassados por gênero, classe e raça, porém acreditamos que é possível produzir brechas no discurso hegemônico por meio da análise destes discursos e da elaboração de outros discursos contra-hegemônicos, voltados à construção de políticas de mudança e de equidade de gênero.

\section{Referências}

ÂNGULO-TUESTA, A. J. Gênero e violência no âmbito doméstico: a perspectiva dos profissionais de saúde. 1997. Dissertação (Mestrado em Ciências na área Saúde Pública) - Escola Nacional de Saúde Pública, Rio de Janeiro, 1997.

BILLIG, M. Ideological dilemmas. London: Sage, 1988.

BRASIL. Ministério da Saúde. Secretaria Especial de Políticas para as Mulheres. Violência intrafamiliar: orientações para a prática em serviço. Brasília, DF, 2003.

CHESNAIS, J. C. A violência no Brasil: causas e recomendações políticas para sua prevenção. Ciência e Saúde Coletiva, Rio de Janeiro, v. 4, n. 1, p. 53-69, 1999.

COULORIS, D. G. Gênero e discurso jurídico: possibilidades para uma análise sociológica. In: CARVALHO, M. J.; ROCHA, S. F. (Org.). Produzindo gênero. Porto Alegre: Sulina, 2004. p. 61-82.

DESLANDES, S. F.; GOMES, R.; SILVA, C. M. F. P. Caracterização dos casos de violência doméstica contra a mulher atendidos em dois hospitais públicos do Rio de Janeiro. Cadernos de Saúde Pública, Rio de Janeiro, v. 16, n. 1, p. 129-137, 2000.

EDLEY, N. Analyzing masculinity: interpretative repertoires, ideological dilemmas and subject positions. In: WHETERELL, M.; TAYLOR, S.; YATES, S. (Org.). Discourse as data: a guide for analysis. London: Sage, 2001. p.184-228.

FAGUTE, M.; LANDIS, L. Barriers to domestic violence help seeking. Violence Against Women,Thousand Oaks, California, v.11, n. 3, p. 29o310, 2005 .

FLITCRAFT, A. et al. Diagnostic and Treatment Guidelines on Domestic Violence. American Medical Association, Chicago, 1992.6p.

FOUCAULT, M. A arqueologia do saber. Rio de Janeiro: Forense Universitária, 1997.

GIFFIN, K. Pobreza, desigualdade e equidade em saúde: considerações a partir de uma perspectiva de gênero. Cadernos de Saúde Pública, Rio de Janeiro, v. 18, p. 103-112, 2002. Suplemento 1. 
GILBERT, G. N.; MULKAY, M. Opening Pandoras'box: a sociological analysis of scientists discourse.

Cambridge: Cambridge University, 1985.

HAGUE, G.; MULLENDER, A. Who listens?: the voices of domestic violence survivors in service provision in United Kingston. Violence Against Women, Thousand Oaks, California, v. 12, n. 6, p. 568-587, 2006.

HEISE, L. Violence against women: the hidden health burden. Washington, DC: World Bank, 1994.

HENNINGTON, E. A. et al. Mortalidade por homicídios em município da região sul do Brasil, 1996-2005. Revista Brasileira de Epidemiologia, São Paulo, v. 11, n. 3, 2008. No prelo.

HYMAN, I. et al. Primary prevention of violence against women. Women Health Issues, Toronto, v. 10, n. 6, p. 288-293, 2000.

IÑIGUEZ, L. (Coord.). Manual de análise do discurso em Ciências Sociais. Petrópolis: Vozes, 2005.

IZUMINO, W. Justiça e violência contra a mulher: o papel do sistema judiciário na solução dos conflitos de gênero. São Paulo: FAPESP, 1998.

KRONBAUER, J. F. D.; MENEGHEL, S. N. Profile of gender violence by intimate partner. Revista de Saúde Pública, São Paulo, v. 39, n. 5, p. 695-701, 2005.

KRUG, E. et al. Informe mundial sobre la violencia y la salud. Washington, DC: OMS: OPAS, 2003.

MENEGHEL, S. N.; IÑIGUEZ, L. Contadores de histórias: práticas discursivas e violência de gênero. Cadernos de Saúde Pública, Rio de Janeiro, v. 23, n. 8, p. 1815-1824, 2007.

MENEGHEL, S. N.; FARINA, O.; RAMÃO, S. R. Histórias de resistência de mulheres negras. Revista Estudos Feministas, Florianópolis, v. 13, n. 3, p. 567584,2005 .

MINAYO, M. C.; SOUZA, E. R. É possível prevenir a violência? Ciência e Saúde Coletiva, Rio de Janeiro, v. 4, n. 1, p. 7-22, 1999.

MORAES, N. A. Discurso, análise do discurso e memória. s.d.Disponível em: <http://www.nilson moraes.pro.br/nm/NM-1pdf.pdf> Acesso em: $30 \mathrm{abr}$. 2007.
GAMEL, M. Nations for Mental Health. A focus on women. Division of Mental Health and Prevention of Substance Abuse. Geneva: WHO, 1997.

OSTERMANN, A. C. Comunidades de prática: gênero, trabalho e face. In: HEBERLE, V.; OSTERMANN, A. C.; FIGUEIREDO, D. (Org.). Linguagem e gênero no trabalho, na mídia e em outros contextos. Florianópolis: Ed. UFSC, 2006. p.15-47.

PALTIEL, F. La salud mental de la mujer de las Americas. In: ORGANIZACION PANAMERICANA DE LA SALUD. Genero, mujery salud en las Americas. Washington, DC, 1993. p. 143-161.

SAFFIOTTI, H. I. B. Gênero, patriarcado, violência. São Paulo: Fundação Perseu Abramo, 2004.

SAFFIOTTI, H. I. B. Gênero e patriarcado. In: CASTILLO-MARTIN, M. (Org.). Marcadas a ferro. Brasília, DF: Secretaria Especial de Políticas para as Mulheres, 2005. p. 35-76.

SAGOT, M. Ruta crítica de las mujeres afectadas por la violencia intrafamiliar en América Latina: estudios de caso de diez países. Washington, DC: OPS, 2000 .

SAGOT, M.; SHRADER, E. La ruta critica que siguen las mujeres afectadas por la violencia intrafamiliar: protocolo de investigación. Washington, DC: OPS, 1998.

SCHRAIBER, L. B.; D'OLIVEIRA, A. F. P. L. Violência contra a mulher: estudo em uma unidade de atenção primária à saúde. Revista de Saúde Pública, São Paulo, v. 36, n. 4, p. 470-477, 2002.

\section{SHALLENBERGER, E. Associativismo cristão:}

Alemanha e sul do Brasil. [S.l.: s.n.], 2007. Disponível em: <http://www.brasilalemanha.com.br/ tese3.htm>Acesso em: 1 jul. 2007.

SCOTT, J. Gênero: uma categoria útil de análise histórica. Educação e Realidade, Porto Alegre, v. 16, n. 2, p. 5-22, 1990.

SERRA, J. C. Navegando entre narraciones: voces que construyen y socavan la credibilidad en ámbito jurídico. Athenea Digital, Barcelona, v. 8, p. 109-128, 2005 . 
SOETHE, J. F. et al. Vale dos Sinos: resgate histórico e visão popular de desenvolvimento. Cadernos Cedope, São Leopoldo, n. 12, p. 3-47, 2001.

SPINK, M. J. Práticas discursivas e produção de sentidos no cotidiano: aproximações teóricas e metodológicas. São Paulo: Cortez, 2000.

SPINK, M. J. Linguagem e produção de sentidos no cotidiano. Porto Alegre: EDIPUCRS, 2004.

STARK, E.; FLITCRAFT, A. Women at risk: domestic violence and women's health. Thousand Oaks, California: Sage, 1996.
STREY, M. Violência e gênero: um casamento que tem tudo para dar certo. In: GROSSI, P.; WERBA, G. (Org.). Violências e gênero: coisas que a gente não gostaria de saber. Porto Alegre: EDIPUCRS, 2001. p. 47-70.

TILDEN, V. P. et al. Factors that influence clinicians' assessment and management of family violence. American Journal of Public Health, Washington, v. 84, n. 4, p. 628-633, 1994.

WHETERELL, M.; POTTER, J. Mapping the language of racism: discourse and the legitimation of exploitation. New York: Columbia University, 1992.

WHETERELL, M.; POTTER, J. El análisis del discurso y la identificación de los repertorios interpretativos. In: GORDO, A.; LINAZA, J. (Org.). Psicologías, discursos y poder. Madrid: Visor, 1996. p. 63-78. 